\section{FROM TRANSLATOR TO TECHNICAL WRITER: A SMALL LEAP}

Karin Montin

\section{My Job}

I work for AES Data Inc., one of the top three manufacturers of word processors in the world.

In August $I$ answered an advertisement for senfor technical witers. I applied although I did not have the required experience. In the end, there was also an opening for a funior technical writer, which I filled.

I had finished my M.A. in translation (French into English) in May and had been looking for jobs in translation, whether free-lance or full-time. There was not a lot of translation work available, and I decided that 1 had done enough writing throughout my educational career to be able to call myself a writer.

In fact, during the two years I spent training to be a translator, my English improved almost as much as my French. When we translated something, the English had to be impeccable: punctuation, typing conventions, spelling, and idfom were all rigorously checked.

\section{The Interviow}

My interview with the personnel department covered everything on my résumé starting with my high school courses. Why had I chosen one course rather than another? How had I become interested in languages?

Which courses had I taken at Cegep (two-year college), McGill, the Université de Montréal? What were my part-time jobs like?

A great deal of emphasis was laid on teamwork. Had teamwork been involved in any of the projects 1 had prepared for my courses? Did I enjoy working with others?
I had to admit that $I$ had done little teamwork, but I sald I was w111ing to try.

I was asked where I would like to be five years from now. I was asked If I had previously considered a career as a writer, especially as a technical writer.

other questions dealt with the task of writing. How did I go about writing something?

First I decide on the topic, then I go to the library and do the research, taking notes and photocopying articles. Then I go home, organize my notes and write the paper. Rereading, of course, is an absolute necessity.

How did I know when something was well written?

I replied that if it read well, it was well-written. I read to see if the sentences hang together and flow from one to the next. The whole paper has to be coherently structured, and each sentence has to be grammatically, logically, and stylistically satisfactory.

Although I had no job experlence as a writer, let alone a technical writer, I emphasized the fact that a translator--a good one, at any rate--must be a good writer. A translator's ideas are perhaps not original, but the prose has to be decent.

I was told that a technical writer was expected to do research. I stressed the fact that a translator must thoroughly research a field before undertaking to translate a text. I had also done a great deal of research for other university courses in a variety of disciplines: anthropology, linguistics and political science, for example.

I listed the areas I had researched for a course in technical translation. They ranged from geomagnetic force fields to nuclear reactors to medical genetics. One text was even on microprocessors.

Then I was left to write a test. 


\section{The Test}

The test was divided into three parts: writing, editing, and spel1Ing. I had an hour.

The writing test was first. This is what it said:

You are provided with a hypothetical block of wood, 4" $\times 4 " \times 4 "$, and an adequate supply of hypothetical paper and twine.

Your audience is a reasonably intelligent group of totally inexperienced trainee block-wrappers. The level of formal education varies widely.

Describe clearly and concisely how to wrap the wooden block.

Time allowed: Up to 30 minutes.

The rest of the page was blank.

This threw me: I had not expected to have to do any technical writing so soon. I thought of all the instructions $I$ had ever read and all the presents I had ever wrapped.

I numbered the steps and made them short. When I had finished, I was not entirely satisfled with my attempt, but I decided to go on with the rest of the test.

\section{The Editing Test}

In the next part of the test I had to edit an ill-written version of the same exercise. It was not too difficult. I had had a course in revising translations, so I even knew some editing symbols.

After reading it carefully, I incorporated into my own instructions an element or two that I had not explained as well.
I later found out that not only was using or even copying outright the instructions in the editing test allowed, it was regarded favourably. Using existing material is considered an efficient means of producing documentation quickly.

\section{The Spelling Test}

The spelling test was a proofreading aptitude test. There was a long paragraph containing a lot of tricky words. I had to write the correct spelling for those that $I$ knew were wrong and indicate those I would check in the dictionary.

There was a short section in which to fill in the missing letter: comput_r, deduct_ble, depend_nt, sep_rate, resist_nt and so on.

\section{Those Who Did Best}

Those who did best on the writing test were those who wrote short, simple, logically organized instructions. They drew pictures. In fact, not many people did 1llustrate the steps in their instructions, but the question did not make it clear that pictures were desirable or even permissible. The next version of the test will encourage people to draw diagrams, without actually telling them to do so.

It is important for writers at AES to be able to visualize what they want to teach. We must be extremely explicit in our instructions to the graphics department--in fact we have to do preliminary sketches ourselves, as well as detafled outlines of what the finished art is to look like.

\section{Style}

When we write the manuals, we are aiming at a target population whose average level of education is high school. The average reading level is about grade six. 
Our philosophy, then, is to write in short, uncomplicated sentences. We apply Flesch's principles of clear writing to a structure combining Information Mapping and Criterion-Referenced Instruction.

Information Mapping Involves labelling paragraphs (or blocks) and pages (or maps). We explain only one new idea per page.

Criterion-Referenced Instruction is instruction that addresses 1 tsel to the questions: What is 1 t that you want the student to be able to do? How will you know when the student can do it?

It is often more difficult to answer these questions than it might seem. Answers that do not involve a "doing" verb are not admissible.

"I want the student to know how to repaginate a text" is not good enough. The answer must be "I want the student to be able to repaginate a text so that each page is a given length." The objective must be a demonstrable skill.

The whole course is structured logically according to what a student needs to know before going on to learn something else. Everything you want to teach must be defined by its prerequisites.

Through a rigorous analysis, we discovered that in our manuals there was no real progression in the sequence of instructions taught. We analyzed all the instructions to determine which ones were prerequisite to others.

Often it is possible to teach tasks independently, although they are applied together as part of another task.

Sometimes that is preferable. For example, it is possible to teach the embedded commands for automatic page numbering without teaching the instructions for headers and footers. Automatic page numbering is more efficiently applied with these features, however, so they are taught in the same lesson.
To take an opposite case, we would not ask students to use file assemble in a proportional print lesson, for example.

We $11 \mathrm{mit}$ the instructions used in a lesson to what is actually being taught in $1 t$. Standard instructions such as recall, memorize, and update are used, of course, but nothing complicated.

\section{Research}

The research I do as a technical writer is quite unlike the research I did as a student.

Then, research was reading. Now, research is experimenting with new functions. Some preliminary reading is involved: first I read the functional specifications. The specs outline the way a feature is supposed to work: which keys to press, what the options and limitations are, how to use the feature. I try out different ways of using the feature. The lessons interpret the specs for the learners.

\section{Conclusion}

We test our lessons by having actual members of our target population try them out. They let us know which parts of which lessons need more explanation and which need less.

Because of their familfarity with the systems, writers sometimes lose their perspectives on the difficulty of an operation. Watching a novice learning gives you a very good illustration of what is hard and what is easy to understand. It is frustrating to find that what you thought you had carefully explained, is in fact incomprehensible.

It is a challenge explaining complicated operations in easy-tounderstand language, and one which I thoroughly enjoy. 